\title{
Kedi ve Köpeklerde Sezaryen ve Piyometra Operasyonlarında Anestezi
}

\section{Teknikleri}

\section{Damla Tuğçe OKUR ${ }^{1 a}$, Bülent POLAT ${ }^{1 b \bowtie}$}

1. Atatürk Üniversitesi, Veteriner Fakültesi, Doğum ve Jinekoloji Anabilim Dalı, Erzurum, TÜRKiYE. ORCID: 0000-0003-2733-2155a , 0000-0002-1790-6808

\begin{tabular}{|c|c|c|}
\hline $\begin{array}{c}\text { Geliş Tarihi/Received } \\
\text { 06.08.2019 }\end{array}$ & $\begin{array}{c}\text { Kabul Tarihi/Accepted } \\
16.12 .2019\end{array}$ & $\begin{array}{c}\text { Yayın Tarihi/Published } \\
30.04 .2020\end{array}$ \\
\hline $\begin{array}{l}\text { u makaleye atıfta bulunmak i } \\
\text { kur DT, Polat B: Kedi ve Köpє } \\
\text { et. Bil. Derg.,15(1): 84-90, } 202\end{array}$ & $\begin{array}{l}\text { ticle: } \\
\text { je Piyometra Operasyo } \\
\text { lataunivbd.601974 }\end{array}$ & Teknikleri. Atatürk Üniversitesi \\
\hline
\end{tabular}

Öz: Veteriner doğum ve jinekolojide sıklıkla uygulanan sezaryen ve piyometra operasyonlarında hem hastanın ağrı ve acı hissini ortadan kaldırmak hem de hekim ve yardımcılarının güvenliğini sağlamak amacıyla anestezik maddeler kullanılmaktadır. Sezaryen ve piyometra operasyonlarında yapılan premedikasyon, preoperatif dönemde yapılacak intravenöz kateterizasyon ve oksijenizasyon sırasında annede oluşabilecek stres ve kaygıyı önler. Bununla birlikte dengeli ve etkili bir premedikasyon, indüksiyon için kullanılacak anestezik madde miktarının azalmasına neden olur. İndüksiyon için sedatif-hipnotik (tiyopental, propofol, alfaksalon, etomidat), dissosiyatif (Ketamin HCL) ve inhalasyon ajanlar (izofluran, sevofluran, desfluran) sıklıkla kullanılmaktadır. Gebe hayvanlarda kullanılacak anestezik ve analjezik maddeler fiziko-kimyasal özellikleri nedeniyle etkilerini kan-beyin bariyerini geçerek gösterir. Bu durum anestezik maddelerin, plasental bariyeri de kolayca geçerek fetüs üzerinde olumsuz etkiler görülmesine yol açar. Yavruları etkilemeden sadece anneyi anesteziye alabilecek bir protokol yoktur. Bu nedenle hem anneyi hem de yavruyu en az şekilde etkileyen bir anestezi protokol seçilmelidir. Piyometralı hayvanlarda ise başlıca; böbrek yetmezliği, kardiyak aritmi ve hepatik işlev bozukluğu gözlendiğinden, bu sorunlara karşı uygun anestezi protokolü seçilmelidir. Bu derleme sezaryen ve piyometra operasyonlarına alınacak hastalarda kullanılabilecek güvenli ve etkili anestezik maddeler ve anestezi protokolleri hakkında bilgi vermek amacıyla hazırlanmıştır.

Anahtar Kelimeler: Anestezi, Kedi, Köpek, Piyometra operasyonu, Sezaryen operasyonu.

\section{Anesthesia Techniques in Cesarean and Pyometra Operations in Cats and Bitches}

Abstract: Anesthetic substances are used in cesarean and pyometra operations, which are frequently applied in veterinary birth and gynecology, both to eliminate the feeling of the ache and the pain of the patient and to ensure the safety of physicians and their assistants. Premedication, carried out in cesarean and pyometra operations, prevents stress and anxiety that may occur in the mother during the oxygenation and intravenous catheterization that will be applied in preoperative period. However, a balanced and effective medication causes to reduce the amount of anesthetic substance to be used for induction. Sedative-hypnotic (thiopental, propofol, alfaxalone, and etomidate), dissociative (Ketamine $\mathrm{HCL}$ ) and inhalation agents (isoflurane, sevoflurane, and desflurane) are frequently used for induction. Due to their physicochemical properties, the anesthetic and analgesic substances to be used on pregnant animals show their effects by crossing the blood-brain barrier. This situation causes the anesthetic substances can pass easily the placental barrier and to be seen adverse effects on the fetus. There is no protocol that can only anesthetize the mother without affecting the offspring. Therefore, anesthesia protocol that affects minimally both mother and offspring should be chosen. As in pyometra animals, renal failure, cardiac arrhythmia and hepatic dysfunction are observed, an appropriate anesthesia protocol should be chosen against these problems. This compilation is prepared to give information about safe and effective anesthetic substances and anesthesia protocols that can be used on patients undergoing cesarean and pyometra operations.

Keywords: Anesthesia, Bitch, Cat, Cesarean operation, Pyometra operation. 
GiRiş

Y unanca Anaistesia'dan türetilen ve "insancıllık" anlamına gelen anestezi terimi, vücudun tamamında veya herhangi bir yerinde sağlanan duyu kaybı olarak tanımlanır. Anestezi, sinir dokusunun aktivitesinin bir ilaç veya ilaç kombinasyonu tarafından lokal, bölgesel veya merkezi sinir sisteminin (MSS) baskılanmasıdır (1). Insan ve veteriner hekimliğindeki operatif müdahaleler sırasında; canlının ağrı ve acı duymasını engellemek, zindeliğini korumak ve iyileşmenin çabuk olabilmesi yönünden anestezinin önemi büyüktür ve tüm bunların ışı̆ıında Anesteziyoloji ve Reanimasyon fikri doğmuştur (2). Anestezik maddeler ameliyat edilecek hastalarda immobilizasyon, kaslarda gevşeme, bilinçsizlik ve ağrı duyusunun ortadan kalkmasını sağlar. Anestezi bu etkileri sayesinde; ameliyat sırasında ağrı ve acı hissinin ortadan kalkması sonucu hastaya müdahale edebilme imkânı vermesi ile bu süreçte hekim ve yardımcıların güvenliğini sağlaması gibi iki önemli amaca hizmet eder (3).

\section{SEZARYEN OPERASYONU}

Sezaryen operasyonu, gebeliğin herhangi bir döneminde, doğumdan önce ya da doğum sırasında, anneye zarar vermeden yavru veya yavruların uterustan uzaklaştırılmasıdır (4).

\subsection{Sezaryen Operasyonunda Hastanın Anesteziye} Hazırlanması

Sezaryen operasyonu için ideal anestezi protokolünü; anne ve fetüsün sağlığını tehlikeye atmadan, operasyon şartlarını yerine getirebilecek düzeyde analjezi, kas gevşemesi, sedasyon ve anestezi oluşturmaktadır (3,5-7). Gebe hayvanlarda kullanılacak anestezik ve analjezik maddeler fizikokimyasal özellikleri nedeniyle etkilerini kan-beyin bariyerini geçerek gösterir. Kan-beyin bariyerini geçebilen anestezik maddeler, plasental bariyeri de kolayca geçerek fetüs üzerinde etkili olmaktadır $(8,9)$. Anestezik maddelerin neden olduğu depresyon ve yaşam riski, anne ve yavruda eşit düzeydedir (3).
Fakat bu etkileri minimize etmek için birkaç seçenek bulunmaktadır. Bunlar;

Lokal anestezi tekniği kullanmak,

Annede istenilen düzeyde anestezi oluşturmak için gereken dozun $1 / 4-1 / 8^{\prime} i$ kadar anestezik ilaç kullanmak,

Propofol gibi kısa sürede indüksiyon ve uyanma sağlayan anestezik maddelerden faydalanmak, Uyanma sürecini kolaylaştırmak amacıyla anestezik maddelerin antagonisti olanları tercih etmek,

Hastanın inhalasyon anestezisine maruz kalma süresini minimuma indirmektir (10).

\subsection{Sezaryen Operasyonunda Kullanılan Anestezik Maddelerin Etkileri}

\subsubsection{Premedikasyon}

Premedikasyon hastanın anesteziye kolay bir şekilde girmesini, eksitasyon dönemi olmaksızın anestezinin devam etmesini ve hastanın anesteziden sakin bir şekilde çıkmasını sağlar (11). Preoperatif dönemde yapılacak intravenöz kateterizasyon ve oksijenizasyon sırasında annede oluşabilecek stres ve kaygıyı önler. Bununla birlikte dengeli ve etkili bir premedikasyon, indüksiyon için kullanılacak anestezik madde miktarının azalmasına neden olur (12). Sezaryen operasyonunda premedikasyon amacıyla antikolinerjikler, trankilizanlar, sedatifler ve opioidler kullanılmaktadır (13). Antikolinerjiklerden glikopirolat'ın plasentaya geçişi kolay olmadığından sezaryen operasyonunda preanestezik ajan olarak tercih edilmektedir (13).

Sedatif ve trankilizan etki oluşturmak amacıyla kullanılan fenotiyazin, benzodiazepin ve $\alpha_{2}$ adrenoreseptör agonistlerinin hızlı bir şekilde plasentayı geçmesi, yavrunun solunum ve kardiyovasküler sistemi üzerinde uzun süreli depresif etki oluşturması nedeniyle bu grupta yer alan ajanların sezaryen operasyonunda kullanımı endike değildir $(3,5)$. 
Fenotiyazin türevi olan asepromazin, maternalfetal depresyona ve termoregülasyon mekanizmasında aksaklıklara neden olmaktadır. Sekiz saatten fazla süren bu olumsuz etkiler, annenin MSS'inde depresif etki oluşturarak, hipotansiyona neden olur. Bu tür anestezik maddelerin düşük dozda kullanımının bile anne ve yeni doğan üzerinde depresif etki oluşturması nedeniyle sezaryen operasyonlarında tercih edilmemelidir. $(3,5,14,15)$.

Benzodiazepin türevi olan diazepam ve midazolam yeni doğanlarda depresyon, letarji, hipotermi, hipotonus ve apneye neden olur (5). Fetal karaciğerin benzodiazepinleri metabolize edebilecek hepatik enzim sistemine sahip olmaması nedeniyle yeni doğanlarda doza bağlı olarak uzun süreli sedasyon oluşabilir. Bu etki doğumdan sonra benzodiazepinlerin antagonisti olan flumazenil ile tersine çevrilebilir. Midazolamın diazepamdan daha kısa etki süresine sahip olması ve suda çözünebilme özelliği nedeniyle sezaryan operasyonlarında tercih edilebilir (12).

Sedatifler arasında yer alan $\alpha 2$ adrenoreseptör agonisti anestezik maddelerin antagonistleri uygulandığı zaman, annede oluşan yan etkiler ortadan kaldırılabilirken, yeni doğan üzerinde oluşabilecek yan etkilerin giderilmesi oldukça zordur. Yapılan çalışmalarda ksilazinin yeni doğan yavrular üzerinde en yüksek mortalite oranına sahip preanestezik madde olduğu belirtilmiştir. Bu grupta yer alan anestezik maddelerin uterus kontraksiyonlarını artırması nedeniyle gebeliğin erken veya geç dönemlerinde kullanımı abortu indükleyebilir. Ayrıca uterustaki kan sirkülasyonunu ve oksijen kapasitesini azaltmaları, anne ve fetüsün arteriyel oksijen basıncında $(\mathrm{PaO} 2)$ ve $\mathrm{pH}$ değerlerinde düşüşe neden olabilir. Bu sebeple ksilazinin gebelikte kullanımı kontrendikedir $(5,16,17)$. Bununla birlikte, yapılan bir çalışmada, medetomidin'in $\alpha 2$ adrenoreseptör agonisti grubunda yer alan diğer anestezik maddelere göre zararlı bir etkisi olmadığı bildirilmiştir (7).

Plasentayı hızla geçen anestezik maddelerden bir diğeri olan opioidler annede sedasyon ve analjezi sağlar. Bu grupta yer alan anestezik maddeler anne ve yavru üzerinde minimal kardiyak depresyona neden olur (12). Fakat doz aşımına bağlı olarak fetüsün respirasyonunu ve sentral sinir sistemini deprese eder $(3,18)$. Bu nedenle solunumu deprese olan ve sürekli uyku halinde bulunan yeni doğan yavrular anneyi ememez. Yeni doğan yavrularda, opioidlerin bu etkileri 24 saat boyunca devam eder ve vücuttan tamamen atılımı 2-6 gün sürer $(3,5,18)$. Opioidlerin antagonistleri de direkt plasentayı geçer. Operasyon sonrası yeni doğan yavruların dil altına 12 damla naloksan gibi antagonist ilaçlardan damlatılarak oluşabilecek yan etkiler ortadan kaldırılabilir $(5,18)$. Bir başka yan etkisi ise annede ve yavruda bradikardi oluşumuna neden olmasıdır. Sezaryen operasyonu uygulanan hastalarda opioid kaynaklı bradikardiyi tersine çevirmek için glikopirolat yerine atropin (0.01-0.02 mg/kg, IV veya $0.02-0.04 \mathrm{mg} / \mathrm{kg}$ SC veya IM) tercih edilmelidir. Çünkü küçük moleküler yapıya sahip olan atropin plasental bariyeri kolayca geçer ve fetal bradikardi ile mücadele eder. Büyük moleküler yapıya sahip olan glikopirolat ise plasental bariyeri geçemez (12).

\subsection{2. İndüksiyon}

Sezaryen operasyonunda sedatif-hipnotik (tiyopental, propofol, alfaksalon, etomidat), dissosiyatif (Ketamin HCL) ve inhalasyon ajanlar (izofluran, sevofluran, desfluran) indüksiyonu sağlamak için sıklıkla kullanılmaktadır. Sedatifhipnotik grubunda yer alan anestezik maddelerin plasental geçişi kolay olmasına rağmen, fetal metabolizasyonu hızlıdır $(5,19)$. Bu nedenle de sedatif-hipnotik ajanların sezaryen operasyonunda kullanımı endikedir $(5,20)$.

Sedatif-hipnotik grubunda yer alan tiyopental'in kardiyovasküler ve solunum fonksiyonları üzerindeki farmakolojik etkileri; kardiyak outputun oluşması, arterial basıncın azalması ve periferik vasküler dirençteki değişikliklerdir. Tiyopental annede apne oluşmasına neden olabilir. Apneye bağlı fötal hipoksi gelişebilir, fakat bu durum preoperatif oksijen desteğiyle ortadan kaldırılabilir. Tiyopental iv 
uygulandığında hızlı indüksiyon sağlayabilmektedir. Tiyopentale bağlı gelişen yan etkiler düşük dozda (<4 $\mathrm{mg} / \mathrm{kg}$ ) uygulandığı zaman azaltılabilir $(5,19)$.

Propofolün kardiyovasküler ve solunum sistemi üzerindeki farmakolojik etkileri tiyopental ile aynıdır. Hızlı indüksiyon ve plasental geçiş sağlar (5). Neonatal dolaşımda kısa sürede metabolize olur ve atılır (3).

Etomidat, kısa etkili bir hipnotik ajandır. Kardiyovasküler sistemde yan etki oluşturmadan hızlı indüksiyon sağlar (5). Tiyopentale kıyasla fetal mortalite oranı yüksektir. Premedikasyon yapılmayan hastalara yalnızca etomidate kullanıldığında kusma, ağrı ve istemsiz hareketler ortaya çıkabilir. Oluşabilecek yan etkilerin önüne geçmek için indüksiyon öncesi preanestezik ilaçlar kullanılmalıdır (20).

Alfazalon, daha az kardiyopulmoner depresyona neden olan kısa süreli etki gösteren bir anestezik maddedir. Ayrıca anestezinin devamı için inhalasyon ajanlar yerine propofol ve alfazolen güvenli bir şekilde kullanılabilir (21).

Anesteziyi indüklemek amacıyla kullanılan bir diğer grup ise dissosiyatiflerdir. Bu grupta yer alan ketamin $\mathrm{HCl}$, kedi (3-5 mg/kg IV) ve köpeklerde (2-4 $\mathrm{mg} / \mathrm{kg}$ IV) düşük dozlarda kullanılabilir. İnsan sezaryen operasyonlarında ketamin $\mathrm{HCl} 1 \mathrm{mg} / \mathrm{kg}$ dozunda kullanıldığında bebekte minimum depresif etki oluştururken (13) insanlara kıyasla kedi ve köpeklerde daha yüksek dozlarla indüksiyon sağlandığı için, neonatal solunum depresyonu oluşma riski daha fazladır. Yapılan retrospektif çalışmalarda da ketamin ile indüklenen anestezi sonrası, yeni doğanlarda mortalite oranının yüksek olduğu bildirilmiştir $(5,14,15)$.

Sezaryen operasyonlarında, inhalasyon ajanlar indüksiyonu ve anestezinin devamını sağlamak için sıklıkla tercih edilmektedir. Bu ajanların plasentayı kolay geçebilmeleri nedeniyle annede oluşan anestezi derinliği ile yeni doğan yavrulardaki solunum ve kardiyovasküler depresyon doğru orantılıdır
$(3,5,18)$. Annede oluşan anestezinin derinliğine bağlı olarak; maternal hipotansiyon, uterus kan akışında azalma ve fetal asidoz şekillenebilir $(3,5)$. İzofluran, sevofluran ve desfluran gibi inhalasyon ajanları ile indüksiyonda, anesteziden uyanma ve oluşabilecek yan etkilerin ortadan kalkması oldukça hızlıyken, haloten'de ise bu etkiler daha uzun sürede gerçekleşmektedir $(3,5)$. İnhalasyonda kullanılan anestezik maddelerin etkilerini güçlendirmek için kullanılan nitrik oksit, uygulanacak olan toplam anestezik madde miktarını azaltır (5).

Sezaryen operasyonunda özellikle epidural anestezi tekniğinde lokal anestezik maddeler kullanılmaktadır. Lokal anestezik maddeler genellikle diğer anestezik maddelerle birlikte veya tek başlarına bölgesel olarak kullanılabilir. Lokal anestezik maddeler ester ve amid grubu olmak üzere ikiye ayrilır. Ester grubunda yer alan prokain, tetrakain, benzokain gibi anestezik maddeler maternal ve fetal psödokolinesteraz tarafından metabolize edilir. Amid grubunda yer alan anestezik maddeler lidokain, mepivakain, bupivakain ise hepatik mikrozomal enzimlerle metabolize edilir. $\mathrm{Bu}$ nedenle lokal anestezik maddelerin fetüste birikimi azdır (5).

Lidokain ve mepivakain gibi lokal anestezik maddeler $3 \mathrm{pg} / \mathrm{mL}^{\prime}$ den fazla kullanıldıklarında neonatal depresyona neden olabilir. Epidural ve paravertebral uygulamalar sonrası yoğun ilaç birikimi görülebilir. Buna bağlı olarak da annede hipotansiyon ve uteroplasental perfüzyon oluşabilir. Lokal anestezik maddelerin kullanımına bağlı oluşabilecek yan etkileri ortadan kaldırmak için vazopresörler, efedrin ve mefentermin gibi maddeler kullanılabilir $(5,18)$. Fakat epidural anestezi, kafa içi basınç artışı, pıhtılaşma bozuklukları, aplastik anemi, hipovolemi, vertebral deformite veya acil durumlar için kontrendikedir. $\mathrm{Bu}$ durumlarda, genel anestezi kullanılması gerekmektedir (22). Tablo 1'de sezaryen operasyonları için ideal ve düşük maliyetli anestezi protokollerine yer verilmiştir. 
Tablo 1. Sezaryen operasyonunda kullanılan anestezi protokolleri.

Table 1. Anesthesia protocols used in cesarean operation.

\begin{tabular}{ll}
\hline Ideal Anestezi Protokolü & Düşük Maliyetli Anestezi Protokolü \\
\hline Premedikasyon & Premedikasyon \\
Atropin $(0.02-0.04 \mathrm{mg} / \mathrm{kg})$ & Atropin $(0.02-0.04 \mathrm{mg} / \mathrm{kg})$ \\
Hidromorfin $(0.5 \mathrm{mg} / \mathrm{kg})$ veya & Morfin $(0.1-0.2 \mathrm{mg} / \mathrm{kg})$ veya \\
Oksimorfin $(0.05-0.1 \mathrm{mg} / \mathrm{kg})$ veya & Butorfanol $(0.2-0.4 \mathrm{mg} / \mathrm{kg})$ \\
Morfin $(0.1-0.2 \mathrm{mg} / \mathrm{kg})$ veya & \\
Butorfanol $(0,2-0,4 \mathrm{mg} / \mathrm{kg})$ & \\
Indüksiyon & Indüksiyon \\
Midazolam $(0.1-0.2 \mathrm{mg} / \mathrm{kg})$ veya & Midazolam $(0.1-0.2 \mathrm{mg} / \mathrm{kg})$ \\
Fentanil $(5-10 \mu \mathrm{g} / \mathrm{kg})$ veya & \\
Propofol $(2-6 \mathrm{mg} / \mathrm{kg})$ & \\
Anestezinin Devamı & Anestezinin Devamı \\
Izofluran $(\% 0.5-2)$ veya & Izofluran $(\% 0.5-2)$ \\
Sevofluran $(\% 0.5-2)$ & \\
\hline
\end{tabular}

\section{PIYOMETRA}

Piyometra, uzun süre progesteronun etkisi altında kalan ve patolojik değişiklere uğrayan uterusun endometriyum tabakasıyla bakterilerin karşılıklı etkileşimi sonucu oluşan bir uterus enfeksiyonudur $(23,24)$.

\subsection{Piyometa Operasyonunda Hastanın Anesteziye Hazırlanması}

Piyometralı hayvanlarda başlıca; böbrek yetmezliği, kardiyak aritmi ve hepatik işlev bozukluğu gözlendiğinden, bu sorunlara karşı uygun anestezi protokolü seçilmelidir (23). Böbrek fonksiyonlarını değerlendirmek için sıvı girişi ile idrar çıkışı izlenmelidir. Böbrek fonksiyonlarını artırmak için dopamin (0.5-3 $\mu \mathrm{g} / \mathrm{kg} \mathrm{IV})$, diüretiklerden furosemid (2-4 mg/kg iV, iM, SC) veya \%20'lik dekstroz uygulanabilir. Piyometralı köpeklerde operasyon öncesi ve sonrasında oluşabilecek hipotansiyona dikkat edilmelidir. Piyometralı kedi ve köpekler aritmi ve taşikardi yönünden izlenmelidir. Toplam proteini 4 $\mathrm{g} / \mathrm{dL}$ 'den veya albumini $1.5 \mathrm{~g} / \mathrm{dL}^{\prime}$ den düşük olan hayvanlarda, preoperatif kolloid uygulaması yapılabilir. Piyometra gözlenen hastaya uygulanacak anestezi protokolü, taşıdığı risk durumuna göre belirlenmelidir. Sistemik belirtilerin gözlendiği piyometralı hayvanlar, anestezi sırasında dikkatli bir şekilde takip edilmelidir (23). Piyometralı kedi ve köpeklerde genellikle böbrek bozuklukları şekillendiği için halotan, barbitürat ve böbrek yoluyla atılan anestezik maddelerin kullanımı önerilmemektedir (25).

\subsection{Piyometra Operasyonunda Kullanılan Anestezik Madeelerin Etkileri}

\subsubsection{Premedikasyon}

Üriner sistem hastalıklarında premedikasyon amacıyla antikolinerjiklerin kullanımı; kalp hızının ve oksijen tüketiminin artmasına ve kardiyak aritmilere neden olduğu için tercih edilmemektedir. Dehidrasyon, şok ve anemi tablosu gözlenmeyen hastalarda sedatif etki oluşturmak amacıyla asepromazin kullanımı önerilmektedir (11).

Kardiyovasküler depresyonu olan piyometralı hastaların, preanestezik ajanlar kullanılmadan, direkt olarak genel anesteziye alınması gerekir. Premedikasyon yapılan veya yapılmayan hastalarda analjezi amacıyla butorfanol (0.2-0.4 $\mathrm{mg} / \mathrm{kg}$ ) veya oksimorfon (0.05-0.1 mg/kg) kullanılabilir (11). Entübe edilecek hayvanlarda premedikasyon amacıyla vazodilatasyon ve miyokardiyal depresyon oluşturmayan opioid ajanlardan, oksimorfin $(0,05-$ $0.1 \mathrm{mg} / \mathrm{kg}$ ), hidromorfin (0.1-0.2 mg/kg), fentanilden (0.0025-0.005 mg/kg) birisi ile benzodiazepinlerden, diazepam (0.2-0.5 mg/kg), midazolam (0.2-0.5 $\mathrm{mg} / \mathrm{kg}$ ) birisinin kombinasyonu kullanılabilir (1). 


\subsubsection{Indüksiyon}

Piyometra operasyonları hastanın entübe edilip edilmediği yönünden değerlendirilmelidir. Entübasyonun mümkün olmadığı durumlarda, kardiyovasküler stabiliteyi koruması ve aritmilere neden olmaması nedeniyle indüksiyon amacıyla etomidat kullanılabilir. Azaltılmış dozlarda tiyopental sodyum (7-10 mg/kg) ve propofol'ün $(2-6 \mathrm{mg} / \mathrm{kg})$ bu tarz hastalarda kullanımı önerilmektedir. Aritmili köpeklerde, etomidat olmaması durumunda tiyopental ve lidokain ile indüksiyon sağlanabilir (11, 23). Minimal kardiyak depresyona neden olmaları nedeniyle inhalasyon anestezik ajanlardan izofluran ve sevofluran anestezinin devamı için sıklıkla tercih edilmektedir $(11,23)$. Piyometra operasyonunda kullanılan ideal ve düşük maliyetli anestezi protokolleri Tablo 2'de verilmiştir.

Tablo 2. Piyometra operasyonunda kullanılan anestezi protokolleri.

Table 2. Anesthesia protocols used in pyometra operation.

\begin{tabular}{ll}
\hline Ideal Anestezi Protokolü & Düşük Maliyetli Anestezi Protokolü \\
\hline Premedikasyon & Premedikasyon \\
Butorfanol $(0,2-0,4 \mathrm{mg} / \mathrm{kg})$ veya & Atropin $(0.02-0.04 \mathrm{mg} / \mathrm{kg})$ \\
Oksimorfin $(0.05-0.1 \mathrm{mg} / \mathrm{kg})$ veya & Morfin $(0.1-0.2 \mathrm{mg} / \mathrm{kg})$ veya \\
Morfin $(0.1-0.2 \mathrm{mg} / \mathrm{kg})$ & Butorfanol $(0,2-0,4 \mathrm{mg} / \mathrm{kg})$ \\
İndüksiyon & Indüksiyon \\
Propofol $(2-6 \mathrm{mg} / \mathrm{kg})$ veya & Tiyopental $(7-10 \mathrm{mg} / \mathrm{kg})$ veya \\
Tiyopental $(7-10 \mathrm{mg} / \mathrm{kg})$ veya & Propofol $(2-6 \mathrm{mg} / \mathrm{kg})$ \\
Etomidat $(0.15-0.3 \mathrm{mg} / \mathrm{kg})$ & \\
Anestezinin Devamı & Anestezinin Devamı \\
Izofluran $(\% 0.5-2)$ veya & Izofluran $(\% 0.5-2)$ \\
Sevofluran $(\% 0.5-2)$ & \\
\hline
\end{tabular}

\section{SONUÇ}

Tıbbi uygulamalar için anestezi gerekli bir süreçtir. Planlanan her operasyon öncesi hasta sahibinden anamnez bilgileri alınmalı, hastanın fiziki ve laboratuvar muayeneleri yapılmalıdır. Bulguların tümü değerlendirilerek anestezi için uygun yöntem ve doğru anestezik madde seçimi yapılmalıdır.

\section{Çıkar Çatışması}

Yazarlar, çıkar çatışması olmadığını beyan eder.

\section{KAYNAKLAR}

1. Tranquilli WJ., Thurmon JC., Grimm KA., 2007. Lumb and Jones Veterinary Anesthesia And Analgesia. 4th ed., 330-335, Blackwell Publishing, Britain.

2. Koç B., Sarıtaş Z., Şener O., 2004. Veteriner Anesteziyoloji ve Reanimasyon. 1th ed., 69-71, Medipress, Malatya.

3. Topal A., 2005. Veteriner Anestezi. 1th ed., 143147, Nobel Tıp Kitapevleri, Bursa.
4. Anadol E., Gültiken N., 2014. Kedi ve köpeklerde güç doğum olgusuna şirurjikal yaklaşım ve anestezi seçenekleri. Dicle Üniv Veteriner Fakültesi Dergisi, 1, 15-40.

5. Tranquilli WJ., Thurmon JC., Grimm KA., 2015. Lumb and Jones Veterinary Anesthesia And Analgesia. 5st ed., 330-335, Blackwell Publishing, Britain.

6. Clarke KW., Trim CM., Hall LW., 2014. Veterinary Anaesthesia. 11th ed., 587-598, Saunders Elsevier, Britain.

7. De Cramer KGM., Joubert KE., Nöthling JO., 2017. Puppy survival and vigor associated with the use of low dose medetomidine premedication, propofol induction and maintenance of anesthesia using sevoflurane gas-inhalation for cesarean section in the bitch. Theriogenology, 96, 10-15.

8. Groppetti D., Di Cesare F., Pecile A., Cagnardi P., Merlanti R., D'Urso ES., Ravasio G., 2019. Maternal and neonatal wellbeing during elective C-section induced with a combination of propofol 
and dexmedetomidine: How effective is the placental barrier in dogs?. Theriogenology, 129, 90-98.

9. Conde Ruiz C., Del Carro AP., Rosset E., Guyot E., Maroiller L., Buff S., Portier K., 2016. Alfaxalone for total intravenous anaesthesia in bitches undergoing elective caesarean section and its effects on puppies: A randomized clinical trial. Vet Anaesth Analg, 43, 281-290.

10. Self I., 2019. Anaesthesia for canine caesarean section. Companion Anim, 24, 84-90.

11. Koç B., Sarıtaş Z., Şenel O., 2012. Veteriner Anesteziyoloji ve Reanimasyon. 2ed., 69-71, Malatya, Medipress.

12. Mathews KA., Sinclair M., Andrea MS., Tamara G., 2018. Analgesia and Anesthesia for the III or Injured Dog and Cat. 1th., 279, USA, Wiley Blackwell.

13. Kanay B., Altan S., 2015. Gebe hayvanlarda anestezi yöntemleri. Turkiye Klinikleri J Vet Sci, 1, 52-57.

14. Moon PF., Erb HN., Ludders JW., Gleed RD., Pascoe PJ., 2000. Perioperative risk factors for puppies delivered by cesarean section in the United States and Canada. J Am Anim Hosp Assoc, 36, 359-368.

15. Moon Massat PF., Erb HN., 2002. Perioperative factors associated with puppy vigor after delivery by cesarean section. J Am Anim Hosp Assoc, 38, 90-96.

16. Lemke KA., 2004. Perioperative use of selective alpha-2 agonists and antagonists in small animals. Can Vet J, 45, 475.
17. Sinclair MD., 2003. A review of the physiological effects of $\alpha 2$-agonists related to the clinical use of medetomidine in small animal practice. Can Vet J, 44, 885.

18. Clarke K., Trim C., Hall L., 2014. Veterinary anesthesia. 11th ed., 19-63, Saunders, Elsevier, Britain.

19. Traas A., 2008. Surgical management of canine and feline dystocia. Theriogenology, 70, 337342.

20. Doebeli A., Michel E., Bettschart R., Hartnack S., Reichler IM., 2013. Apgar score after induction of anesthesia for canine cesarean section with alfaxalone versus propofol. Theriogenology, 80, 850-854.

21. Robertson, S., Anaesthetic management for caesarean sections in dogs and cats. In Practice, 2016. 38, 327-339.

22. Hu L., Pan J., Zhang S., Yu J., He K., Shu S., Wang R., 2017. Propofol in combination with remifentanil for cesarean section: Placental transfer and effect on mothers and newborns at different induction to delivery intervals. Taiwan J Obstet Gynecol. 56, 521-526.

23. Fossum T.W., 2013. Small Animal Surgery Textbook-E-Book. 6th ed., 737-741, Elsevier Health Sciences, Philadelphia.

24. Alaçam E., 2010. Evcil Hayvanlarda Doğum ve Infertilite. 7th ed., 391, Medisan Yayınevi, Ankara.

25. Özyurtlu N., 2012. Köpeklerde piyometra ve tedavi seçeneklerine kısa bir bakış. Dicle Üniversitesi Veteriner Fakültesi Dergisi, 2012, 34-36. 